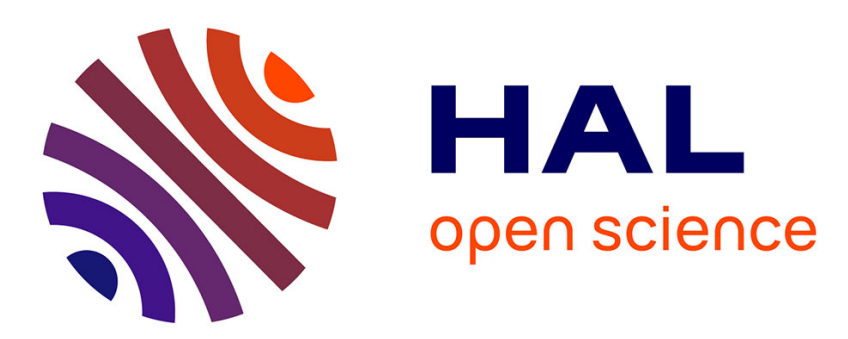

\title{
Spatial econometrics of innovation: Recent contributions and research perspectives
}

Corinne Autant-Bernard

\section{To cite this version:}

Corinne Autant-Bernard. Spatial econometrics of innovation: Recent contributions and research perspectives. 2011. halshs-00605056

\section{HAL Id: halshs-00605056 \\ https://shs.hal.science/halshs-00605056}

Preprint submitted on 30 Jun 2011

HAL is a multi-disciplinary open access archive for the deposit and dissemination of scientific research documents, whether they are published or not. The documents may come from teaching and research institutions in France or abroad, or from public or private research centers.
L'archive ouverte pluridisciplinaire HAL, est destinée au dépôt et à la diffusion de documents scientifiques de niveau recherche, publiés ou non, émanant des établissements d'enseignement et de recherche français ou étrangers, des laboratoires publics ou privés. 
Spatial econometrics of innovation:

Recent contributions and research perspectives

Corinne Autant-Bernard

Juin 2011 


\section{GATE Groupe d'Analyse et de Théorie Économique Lyon-St Étienne}

93, chemin des Mouilles 69130 Ecully - France

Tel. +33 (0)4 72866060

Fax $+33(0) 472866090$

6, rue Basse des Rives 42023 Saint-Etienne cedex 02 - France

Tel. +33 (0)4 77421960

Fax. $+33(0) 477421950$

Messagerie électronique / Email : gate@gate.cnrs.fr

Téléchargement / Download : http://www.gate.cnrs.fr - Publications / Working Papers 


\title{
Spatial econometrics of innovation:
}

\section{Recent contributions and research perspectives}

\author{
Corinne AUTANT-BERNARD \\ Université de Lyon, Lyon, F-69003, France ; Université Jean Monnet, Saint-Etienne, \\ F-42000, France ; CNRS, GATE Lyon St Etienne, Saint-Etienne, F-42000, France \\ e-mail: corinne.autant@univ-st-etienne.fr
}

\begin{abstract}
:
Preliminary introduced by Anselin, Varga and Acs (1997) spatial econometric tools are widely used in economic geography of innovation. Taking into account spatial autocorrelation and spatial heterogeneity of regional innovation, this paper analyzes how these techniques have improved the ability to quantify knowledge spillovers, to measure their spatial extent, and to explore the underlying mechanisms and especially the interactions between geographical and social distance. It is also argued that the recent developments of spatio-dynamic models opens new research lines to investigate the temporal dimension of both spatial knowledge flows and innovation networks, two issues that should rank high in the research agenda of the geography of innovation.
\end{abstract}

Keywords: Geography of innovation, spatial correlation, spatio-dynamic panels, innovation networks

JEL codes: O31, R12, C31 


\section{Introduction}

Spatial econometrics is a subfield of econometrics that has been fastly expanding since the end of the 80s. Spatial econometric tools deal with the spatial dimension of data and especially with the autocorrelation and heterogeneity that is inherent within localized dataset (Anselin 1988). From the seminal work of Paelink and Klaasen (1979) and Anselin (1988) the set of available tools have developed fast, allowing us to test for spatial dependence and to estimate properly several specific models, such as count data models, qualitative data models, panel data models.

Spatial econometric tools have been used in various fields of applied economics (agricultural economics, health economics, growth convergence analysis, marketing studies, more recently fiscal economics, etc), and in particular in the analysis of regional innovation and growth. The use of spatial economics in this last field is something rather obvious. The relation between space and innovation has long been pointed out (Marshall, 1920). In this perspective, the use of spatial econometric tools relies on two main motivations.

Firstly, as stressed by LeSage and Pace (2010), there is an "R\&D-based motivation". The endogenous growth theory relies on the idea that knowledge is at least partly a public good, in the sense that it is only partially appropriated by the agent that produces it. In other words, knowledge can be used by new agent without any cost or at a lower cost that the one that has been requested to produce it. The fact that these knowledge externalities would be spatially bounded is at the heart of the new geography and growth theories to explain agglomeration processes and uneven spatial distribution of economic activities. These knowledge spillovers effects imply that spatial dependence when dealing with innovation data at the regional level.

The second motivation for considering spatial dependence in the innovation process comes from the very strong spatial polarization of economic activities in spacei. This uneven 
distribution means that there is a high spatial heterogeneity in the innovation processes that should be accounted for. Indeed, this heterogeneity is very likely to lead to spatial dependence within the random perturbation of econometric model.

For these reasons, spatial econometric tools have started to be more and more used in the analysis of regional innovation and growth since the end of the 90s. The aim of this paper is therefore to give an overview of the contributions provided by spatial econometric tools in this field, and to draw the main research perspectives, especially the ones resulting from the latest developments of spatio-dynamic models. I will argue that these latter provide us with new tools allowing us not only to deal with the spatial dimension of knowledge diffusion, but also to investigate the role played by time in the innovation process.

To this aim, this paper is organized into three parts. In the first section, the focus is on the contribution provided by spatial econometric tools in the quantification of knowledge spillovers. Section 2 then reviews the studies using spatial econometrics while exploring the mechanisms underlying knowledge spillovers. In this part, special emphasis is put on the approaches investigating the role played by collaboration and networks in spatial knowledge diffusion. Finally, the last section details the most recent developments in spatial-dynamic econometric model and show how they could be used to analyze the spatio-temporal dimension of knowledge diffusion. In each of these three sections, a literature review is provided first, and then research perspectives are discussed. It is important to note that I do not necessarily provide a completely exhaustive literature review on each specific issue (which would require much more than one paper). The aim is rather to put the stress on the main contributions and derive from them some new research questions. 


\section{Using spatial econometric tools to quantify spatial knowledge spillovers}

Following the seminal literature on knowledge spillovers (Jaffe, 1989, Jaffe, Trajtenberg and Henderson, 1993, Audretsch and Feldman 1996), spatial econometric tools have been introduced in the field of geography of innovation in two different frameworks. The first one is detailed below and relies on a knowledge production function. The second one, discussed in the next subsection, is based on a spatial interaction modeling.

\subsection{Spatial knowledge production function}

Spatial econometric tools first enter into the analysis of regional innovation through the knowledge production function setting in which innovation in region is explained by the $R \& D$ inputs carried out locally. In this perspective, the very first introduction of spatial tools is due to Anselin, Varga and Acs (1997) and consist in introducing not only the regional R\&D inputs, but also the R\&D carried out in the surrounding regions. Then, tests of spatial dependence in the random perturbation can be used to determine the correct level to consider for inter-regional spillovers (Anselin, Varga and Acs, 1997, Maggioni, Nosvelli, Uberti, 2007). The spatial lag is specified so that spatial dependence no longer occurs in the perturbation. In some cases, the presence of spatial autocorrelation is directly interpreted has the (Gallie and Legros, 2007 for instance), and spatially lagged explanatory variables is not introduction into the model, which is more questionable. Indeed, as explained in the next paragraphs, such spatial error models do not really deal with spillovers effects indirect effects between regions are excluded from the model.

Building upon these preliminary approaches, more recent studies have elaborated a little more on the spillovers effects. Mairesse and Mulkay (2007) and Autant-Bernard and LeSage (2010) uses a Spatial Durbin Model, considering both the spatially lagged independent and 
dependent variables. Autant-Bernard and LeSage (2010) provide an empirical motivation for this model. Beginning with a non-spatial knowledge production function we show how the presence of unobserved regional inputs to the knowledge production process lead to a spatial regression model that includes a spatial lag of the dependent variable as well as the independent variables.

Three main contributions result from the introduction of these different spatial econometric tools. The first one is the ability to distinguish direct and indirect impacts thanks to the matrix of own- and cross-partial derivatives. The direct effects capture the response of the innovation output to a change in R\&D input within the area. These direct effects take into account the feedback loops that arise from the bidirectional nature of spatial dependence. Each region being a neighbor for its neighbors, a shock in the inputs of region $i$ that impact on innovation within the region also increases the innovation output at neighbors, which in turn influences innovation in region $i$. The indirect effects on the other hand capture the response of region / to changes in other regions R\&D inputs. In that sense, they can be interpreted as knowledge spillovers.

The second contribution provided by the introduction of spatial econometric tools within the knowledge production function is the ability to analyze the spatial profile of impacts. Within the different effects, it is possible to disentangle the effects arising at the first order neighbor, from those arising at the second order neighbor, third order and so on. The partial derivatives can indeed be used to investigate marginal impacts which show how spillovers decay with respect to order of the neighbors. From this point of view, spatial econometric tools help us to quantify the spatial extent of knowledge spillovers.

Last but not least, the third contribution is the correct calculation of the model coefficients. If not accounted for, spatial dependence generates endogeneity leading conventional model to produce biased and inconsistent estimators (Anselin and Le Gallo, 2006). Spatial 
econometric tools therefore allow us to estimate properly the model parameters. Comparing the estimated coefficients reported by Autant-Bernard and LeSage (2010) using spatial econometric methods to the coefficients that would be computed thanks to conventional methods underlines the potential importance of the endogeneity bias. The Bayesian estimates suggest higher private R\&D spillovers and lower public R\&D spillovers, and they also suggest less resistance of knowledge flows to distance. Spatial knowledge production function therefore produces substantially different results from the one produced by non spatial models, giving a more accurate assessment of spatial knowledge spillovers. The same phenomenon arises for the approaches that rely on spatial interaction models instead of spatial knowledge production function.

\subsection{Spatial interaction model}

Spatial interaction model is the name given to gravity models when they are applied to the field of regional sciences. The basic assumption of the model is that the interaction between two regions (or two agents) depends on the respective weight of each agent together with the distance between them. In this perspective, the analysis of spatial knowledge spillovers relies on patent citations. Since the seminal work by Jaffe, Trajtenberg and Henderson (1993), patent citations have been considered as a proxy for knowledge spillovers. In spite of several limitations discussed for instance in Autant-Bernard et al. (2010), reference made to previous patents can be considered as a paper trail of previous knowledge used in the new invention.

In spatial interaction models, the strength of knowledge spillovers is assessed by introducing spatial distance as an explanatory variable of the intensity of the patent citation flows between regions (LeSage, Fischer, Scherngell, 2007, Fischer and Griffith, 2008, Bergman and Usai, 2009). A Poisson (or binomial negative) model is thus estimated to take 
into account the specificity of the data (count data with a large number of observations). Within this framework, spatial econometric tools improve the ability to measure the spatial dimension of knowledge spillovers in the sense that they permit to correct for spatial autocorrelation resulting from heterogeneity of origin and destination regions (LeSace and Pace, 2010). The usefulness of such a correction is clearly pointed out by Fischer, LeSage, Scherngell (2007). In this paper, they compare the results obtained with their Bayesian spatial Poisson model with those obtained in a previous version of the model (Fischer, Jansenberger, Scherngell, 2006) using conventional estimation methods. It comes out that the Bayesian effects model produces smaller coefficient estimates for both distance and borders. As observed for the spatial knowledge production function approaches above mentioned, less resistance of knowledge flows to distance and borders is observed when unobserved heterogeneity is controlled for using the model containing spatial effects.

\subsection{Research perspectives}

From the two previous sections, it appears clearly that using spatial econometric tools improves the way spatial knowledge flows and their spatial extent is measured. Nevertheless, several research perspectives remain. The first one would be to exploit the information contained in the matrix of direct and indirect impacts. This matrix contains all the responses of the regional outputs to any change in regional inputs. As we are most of the time interested in the global impacts, average direct and indirect impacts are computed. The more detailed information contained in this matrix could however inform us about region-specific effects. In a policy evaluation perspective in particular, the impact of a change in the input of one specific region on all the other regions could be assessed. Conversely, the information given by the own partial derivatives and cross partial derivative 
could help us to evaluate the benefit for each specific region due to a global increase in the R\&D input. To our knowledge, no study has been carried out in this direction yet.

The second research perspective is the introduction of the time dimension within the spatial approaches of innovation. This issue is discussed in detail in the third section of this paper. Before that, section 2 reviews the contribution provided by spatial econometrics to the analysis of the mechanisms driving knowledge spillovers.

\section{Using spatial econometric tools to explore underlying mechanisms of knowledge} diffusion

Building upon the empirical evidence of local knowledge spillovers, several research papers have investigated the potential mechanisms that may explain the spatial bounding of knowledge diffusion. In this perspective, spatial econometric tools have also started to be used, paving the way for further research. In the following sub-sections, we first recall the main arguments developed to explain the role played by spatial proximity. The way spatial tools have been introduced is then analyzed, putting special emphasize on the innovation network analysis, while the last sub-section argues that a lot remains to be done.

\subsection{Why does distance matter?}

The literature provides two main explanations to the polarization of knowledge diffusion in space both of them relying on interpersonal relationship. The common idea is that distance matters because it reduces the opportunity of face to face interactions, which would be an important vector of knowledge diffusion, especially when knowledge has an important tacit component. These interpersonal relationships would in particular be favored by labor mobility on the one hand, and by collaboration network on the other. A first set of studies 
explores the specific role played by labor mobility (Zucker, Darby and Armstrong, 1994, Almeida and Kogut, 1999, Balconi, Breschi and Lissoni, 2004 or more recently Breschi and Lissoni, 2009). Once accounted for labor mobility, the spatial dimension by itself would no longer matter. Ideas would be embodied into people and travel with them. In other words, distance would matter due to the lack of labor mobility through space.

The second channel through which interpersonal relationship would impact on spatial knowledge diffusion is the ability to form collaboration links. Johnson et al. (2006) actually show that collaborations are even more spatially focused than citation is. Two main distinct frameworks have been used to investigate the role played by collaborations in knowledge diffusion. The former relies on patent citations (Singh, 2005, Sorenson et al., 2006, Gomes-Casseres et al., 2006, Agrawal et al., 2008). It demonstrates that if two regions (or two agents) have co-invented a patent, or if these two regions are sufficiently closed in the co-invention network, they are more likely to cite each-other. The spatial clustering of knowledge diffusion would therefore result from the higher opportunities of collaboration offered by co-location. More recently, several authors have adopted a slightly different framework to address this issue, based on collaboration models. The dependent variable is in this case the probability for two agents to collaborate, or the intensity of their collaboration. Using either individual (Autant-Bernard et al. 2007, Frachisse, 2011) or regionally aggregated data (Ponds et al. 2007, Scherngell and Barber, 2009), they assess among the various determinants of collaboration, the specific role played by space. In this perspective, the introduction of spatial econometric tools is very promising. 


\subsection{Two distinct empirical strategies: Spatial knowledge production function and}

gravity models.

The use of spatial econometric tools to explore the role the interactions between space and formation of collaboration ties has followed two directions that address slightly different issues.

Based on the spatial knowledge production setting, a first set of papers studies to what extent geography is a by-product of social proximity (Maggioni and Uberti, 2007, Maggioni et al., 2009). To this aim, a relational weight matrix is introduced and test for spatial dependence are performed once controlled for controlled for social proximity. An alternative approach, not implemented yet to our knowledge, would be to compare different weight matrices using spatial econometric tools like those developed by LeSage and Parent, 2004). This would allow determining whether a spatial weight matrix or a social weight matrix would be more relevant, or if combining both kinds of distance performs better.

The second approach relies on the gravity-like models. Whereas in the previous approach, networks enter into the knowledge production function through the spatial weigh matrix, in this case, as Maggioni and Uberti (2011) argue, space enters into the networks setting. The key issue then becomes "does spatial distance impact on collaboration and network formation?". The use of spatial econometric tools within this framework is suggested by Scherngell and Barber (2009) where spatial dependence arising for spatial heterogeneity is accounted for, making use of a Bayesian spatial interaction model developed in Fischer, LeSage, Scherngell (2007). The empirical results of these studies underline the role of social ties as channels for diffusion of knowledge as well as the interplay between social and geographical proximity. However, the introduction of spatial tools remains unusual and this area is rather an ongoing research field. 


\subsection{Perspectives linking spatial econometrics and network analysis}

The research perspectives are numerous and it is difficult to anticipate all of them. There are at least for areas in which spatial econometric tools might offer a valuable contribution. First of all of course, one can claim for a more systematic accounting for spatial dependence within collaboration gravity models. A part from the noticeable exception of Scherngell and Barber (2009), spatial tools are not yet introduced in this type of setting.

But beyond these spatial interaction models, a promising line of research would require to reverse the causality. While most of the current approaches focuses on the impact of distance on collaboration and network formation, it would be interesting to investigate to what extent collaborations and networks structure impact on geography. In other words, does network positioning of one region and its neighbors impact the regional innovation or the spatial diffusion of knowledge? Spatial econometric techniques would here again be useful to explore this kind of issue. To this regard, the recent contribution by Miguelez and Moreno (2010) provides a first attempt in this direction. The dataset covers NUTS2 regions of 17 Western European countries. In addition to traditional R\&D inputs, the propensity to patent in each region is explained by the mobility of inventors and the main feature of the network to which they belong (strength of links, connectivity and density). A spatial lag model and the robust spatial the spatial heteroskedastic and autocorrelation consistent estimation of the variance-covariance matrix are implemented. The results underline the role played by regional labor mobility but unclear evidence of the role played by networks is provided. The endogeneity problem arising in such a setting still remains to be dealt with.

Another promising area lies on the refining of the relational weight matrix, using textual information. Indeed, most of the innovation network databases - being they coinventions, copublications, R\&D collaborative projects, and so on - contains, along with relational 
information, additional data such as abstracts, keywords, etc. This latter can be used to go beyond the simple definition of social distance between agents based on the participation to a join research. The analysis of the semantic proximity may help us to characterize more precisely the scientific communities and to study how knowledge diffuses through innovation networks In this perspective, Maggioni et al. (2009) exploit the keywords information contained in scientific publications in order to measure the extent of a convergence process of the vocabulary of scientists working in the specific field the "cluster literature" from 1969 to 2007. This preliminary work does open the way for very fruitful analyses based on the recent developments in computer sciences (see Mika et al, 2006 for instance) which would allow us to consider cognitive distance as a key feature to understand the interactions between space and networks.

Last but not least, the introduction of spatial econometrics within network analysis is also going to benefit from the inclusion of the time dimension. This point is further discussed in the section below.

\section{Using spatial econometric tools to investigate the spatio-temporal dimension of} knowledge diffusion

Within the growing field of spatial econometric techniques, one of the most active areas over the last few years is certainly the panel data models where the observational units are regions. These new developments, summarized in the next subsection, offer the possibility to deal at the same time with both the spatial and the temporal dimension. As detailed in the last two subsections, this will allow us to investigate the spatio-temporal dimension of knowledge flows and knowledge networks. 


\section{1. New developments in spatio-temporal models}

Spatio-temporal models belong to the broader category of spatial panel data models (an overview is given by Anselin, Le Gallo, Jayet, 2008 and more recently by Lee and Yu, 2010). Within these models one can distinguish on the one hand models that include the spatial dependence in the error term only and, on the other hand, spatio-temporal lag models that include the spatially and temporally lagged dependent variable.

Space-time dependence in the disturbance structure has been introduced in both static and dynamic models. Baltagi et al. (2007) suggest spatial correlation tests and temporal correlation tests in a panel model with random effects. Kapoor et al. (2007) extend estimation based on the method of moments to a spatial panel model with error components while the extention to the case of a dynamic panel is provided by Su and Yang (2007).

More recent models allow space-time dependence to occur in the dependent variable. This kind of model is labelled spatial dynamic panel data models (SDPD) by Lee and Yu (2010), in reference to the more usual dynamic panel data models where serial correlation occurs in the time dimension only. Estimation of these SDPD models relies either on a frequentist or on a probabilistic approach. Yu et al. (2008) investigate the asymptotic properties of the quasi-maximum likelihood estimators in a static SAR model and Yu and Lee (2010) extend it to the dynamic case. Bayesian approach is an interesting alternative to estimate such models that have correlation in the time dimension as well as spatial correlation across units. Parent and LeSage (2010 and 2011) estimate a model with random effects while Erthur et al. (2010) consider the more elaborated case of a dynamic spatial Durbin model.

Thanks to the presence of an individual time lag, a spatial lag and a cross-product term reflecting the space-time diffusion, the dynamic responses over time and space that arise from changes in the explanatory variables can be calculated (Erthur et al. 2010). These 
methods have been applied to the case of highway induced travel demand (LeSage and Parent, 2009) or to the state-level demand for cigarettes (Erthur et al. 2010). But they are also very promising to investigate the spatio-temporal dimension of knowledge flows.

\subsection{Spatio-temporal dimension of knowledge flows}

The introduction of the time dimension in the applied analysis of knowledge spillovers allows us to deal with several issues that have remained relatively unexplored so far regarding the long-run knowledge production process. From a theoretical point of view, the temporal dimension of knowledge diffusion has long been recognized as a key issue. A tough debate framed by the work of Romer (1990) and Jones (1995) has focused on time dependence in the flow of new ideas. However, if there is no doubt that knowledge accumulated by inventors at one period of time is used by new inventors at the next periods, the mechanisms by which this diffusion occurs has not been deeply investigated yet. In particular, some key issues arise when it comes to consider the spatial dimension of this process: How long does it take for knowledge to flow through space? To what extent does the nature of the agglomeration forces change through time?

From a more applied perspective, taking time into account is also important to better assess the specific role played by space. Indeed, the introduction of the temporal dimension is likely to modify the results obtained from spatial estimation neglecting time. A strong simultaneous spatial dependence can result from a strong time dependence and a weak spatial dependence (LeSage and Pace 2010).

Several empirical approaches have been suggested to deal with these issues. In the agglomeration studies (Glaeser et al. 1992, Henderson et al. 1995, etc) the inter-temporal dimension of externalities is apprehended by taking into account the impact upon growth 
of the initial industrial structure. As has been emphasised by Partridge and Rickman (1999) however, contemporaneous values of the independent variables are often correlated with initial values of these variables, making it to disentangle static from dynamic effects. In addition, this approach does not provide us with a specific evaluation of knowledge spillovers. Some very preliminary insights into this topic can be found in working papers by Jaffe, Trajtenberg and Henderson (1993), more recently Johnson, Sipirong and Brown (2006). Based upon patent citations they point out that geographical coincidence between citing and cited patents decreases over time. Very few studies have been carried out using a knowledge production function framework. Bottazzi and Peri (2007) provide some insight here using time-series. They focus however upon international spillovers only and ignore the space-time dynamics, focusing exclusively on temporal dependence. A more detailed study is provided by Parent (2009). Based on a sample of 49 US states over the period 19942005, Bayesian MCMC approach are implemented to estimate the model parameters which accommodate spatial diffusion of innovative activities in a dynamic framework. The results point to a low level of spatial dependence between neighboring regions. Nevertheless, due to time dependence, this spatial effect can over long time periods lead to a significant amount of inter-connectivity between regions. Additional research in this perspective is for sure a relevant to analyze the long-run spatial knowledge production and diffusion process.

\subsection{Spatio-temporal dimension of knowledge networks}

The latest developments in spatial-temporal econometric models are also very promising to anyone interested in knowledge network formation and evolution. The literature on innovation network brings forth new questions that will probably benefit directly from the new spatial econometric tools. A first set of issues refers to the interactions between space and networks. In this perspective, two main issues are at stake here: To what extent do the 
spatial determinants of collaboration changes through time? To what extent does the spatial structure of network change through time? By taking into account temporal as well as spatial dependence, spatial econometric techniques can contribute to deal with these issues.

A second set of questions that arise in network analysis is related to the dynamics of networks. In this perspective, spatial econometric tools could be used in a slightly different way, by considering social distance instead of spatial distance. Introducing temporal as well as relational dependence into empirical network analysis may be a relevant way to investigate most of the theoretical hypotheses (preferential attachment, closure, etc), conventional methods facing most of the time endogeneity problems. This would allow us to analyse how networks evolve over time and how long it takes for knowledge to flow through networks.

Some studies have started to explore the dynamics of innovation networks, but none of them makes use of spatio-temporal econometric approaches. Using a sample of scientific publications, Hoeckman, Frenken and Tijssen (2010) estimate a gravity model. The results reveal that the effect of territorial borders on co-publishing decreases over time, whereas the effect of distance either remains almost the same or increase in importance. Based on R\&D project data, a similar interaction model is implemented by Lata and Scherngell (2010) in which they account for spatial dependence but not for panel dimension. They observe that the effect of both distance and border on R\&D collaboration gradually declines over time. Focusing on network effects, Hanaki, Nakajima and Ogura (2010) also study the dynamics of knowledge network. Within their co-invention data, cyclic closure and preferential attachment effect is observed, as well as a positive impact of co-location. These approaches are however based on static comparisons. Other approaches such as longitudinal analysis may appear more relevant. Based on stochastic estimation, the 
estimation procedure simulates how the network has evolved from one state into the next. Using the program Simulation Investigation for Empirical Network Analysis (SIENA) developed by Snijders et al. (2007), Ter Wal (2010) investigates the joint effect of geographical proximity and triadic closure in biotech network evolution. As detailed by Ter Wal (2010), the application of such approaches is still limited due to restrictive constrains, but it offers a promising potential for future research.

\section{Conclusion:}

Two essential features characterize the geography of economic activities: considerable spatial concentration on the one hand and the industrial specialization of certain geographical zones on the other hand. Among these economic activities, innovation is no exception being highly concentrated in a small number of countries, and within these countries, in a small number of regions and often in a small number of metropolitan areas within these regions. These agglomerative tendencies of innovative activities are hardly recent. A study of the geography of such activities over the past one hundred years in the United States (Vertova, 2002) shows that the phenomenon is long-standing even though it is now tending to intensify.

Combining the work on endogenous growth (Romer, 1990; Grossman and Helpman, 1995) and on economic geography (Fujita, Krugman and Venables, 1999) enables us to understand this unequal distribution of innovation and the resulting growth dynamics. This understanding is based upon the hypothesis of a local dimension of knowledge externalities. The notion of knowledge externalities is indeed at the base of the concept of increasing returns which is essential for understanding the impact that technological change has upon growth. The spatially bounded nature of these externalities would 
consequently appear to be at the origin of a geographical polarization of innovative activities and localized growth dynamics.

These theoretical advances have opened the way for a number of empirical studies which aim to answer several research questions which are essential in terms of technological policies: What is the magnitude of these externalities phenomena? On what spatial scale can they be found? What are the reasons for the spatial dimension of externalities? Does geographical proximity alone suffice for there to be any benefit from the returns?

In order to deal with these issues, several studies have followed the seminal studies carried out by Jaffe (1989), Jaffe, Trajtenberg and Henderson (1993) and Audrestch and Feldman (1996). In this field of the geography of innovation, theoretical and empirical advances go hand in hand and build upon the methodological improvements of econometric tools.

Preliminary introduced by Anselin, Varga and Acs (1997) spatial econometric tools are widely used in economic geography of innovation. Taking into account spatial autocorrelation and spatial heterogeneity of regional innovation, these techniques have improved the ability to quantify knowledge spillovers, to measure their spatial extent, and to explore the underlying mechanisms and especially the interactions between geographical and social distance.

But these techniques are also very promising of new advances. The recent developments of spatio-dynamic models opens new research lines to investigate the temporal dimension of both spatial knowledge flows and innovation networks, two issues that should rank high in the research agenda of the geography of innovation.

Bayesian econometric techniques may play a key part in these new developments as they overcome several difficulties faced by frequentist approaches (heterogeneity, null observations, model comparison, etc.). Multinomial logit estimations used in location 
choice models require for instance estimating a large number of parameters, which is easier with Bayesian MCMC techniques. Indeed, the computational problems associated with the Hessian calculation in the case of the Maximum Likelyhood estimation that arise when considering large sample or when there is a large number of parameters in the model is overcome. Similarly, the spatial heterogeneity that characterizes in particular individual or relational data is better dealt with by Bayesian tools. Heteroscedasticity can be introduced in the frequentist approaches. However, as stated by Anselin (1988), it requires much more restrictive hypotheses about the form and the origin of this heterogeneity than in the Bayesian approach. This latter also permits to identify outliers. In addition, Bayesian estimates avoid to be locked into a local maximum which could arise with Maximum Likelyhood. Of course, it is worth noticing that bayesian approach assumes that the econometrician has a prior knowledge that allows her to formulate a prior distribution for the parameter, an idea usually not subscribe to by non-Bayesians. When the sample size increases, this prior information tends however to play a minor role in determining the character of the posterior distribution.

In addition to these technical advances, recent researches move to new approaches aiming at exploring the consequences of knowledge externalities at the individual level. More specifically, an important issue deals with the extent to which firms' location choices are influenced by their desire to benefit from these knowledge externalities. To this aim, recent studies measure the impact of spatial knowledge flows upon individual behaviour patterns, in terms of location choice and firms' productivity. Based upon a microeconomic production function, the results demonstrate the impact of such externalities upon firms' productivity (Barbesol and Briant, 2009; Andersson and Lööf, 2009 ; Autant-Bernard et al., 2011; Martin et al., 2011). Using a location choice model also show that the choices made by firms concerning the location of their R\&D laboratories are affected by these externalities, even though other agglomeration forces seem to be stronger (Autant-Bernard, 2006). However, 
including spatially lagged dependent variables only these approaches neglect part of the spatial dependence phenomena. The use of spatial econometrics is probably going to improve these results as well.

\section{References:}

Agrawal A., Kapur D. and McHale J. (2008) How do spatial and social proximity influence knowledge flows? Evidence from patent data, Journal of Urban Economics, 64: 258-269.

Almeida P. and Kogut B. (1999) Localization of knowledge and the mobility of engineers in regional networks, Management Science, 45: 905-917.

Andersson M. and Lööf H. (2009) Agglomeration and Productivity - evidence from firmlevel data, CESIS Electronic Working Paper Series, Paper No. 170, pp. 29.

Anselin L. (1988) Spatial Econometrics, Methods and Models Kluwer Academic, Boston.

Anselin L., Varga, A. and Acs, Z. (1997) Local Geographic Spillovers Between University Research and High Technology Innovations, Journal of Urban Economics, 42: 422-448.

Anselin L. and Le Gallo J. (2006) Interpolation of Air Quality Measures in Hedonic House Price Models: Spatial Aspects. Spatial Economic Analysis, 1(1): 31-52.

Anselin L., Le Gallo J. and Jayet H. (2008) Spatial Panel Econometrics, In L. Matyas and P. Sevestre (Eds.), The Econometrics of Panel Data, Dordrecht, Kluwer.

Audretsch D. and Feldman M. (1996), R\&D Spillovers and the Geography of Innovation and Production, The American Economic Review, 86(3): 630-640. 
Autant-Bernard C. (2006) Where do firms choose to locate their R\&D? A spatial conditional logit on French data, European Planning Studies, 14(9), October.

Autant-Bernard C., Billand P., Frachisse D. and Massard N. (2007) Social distance versus spatial distance in R\&D cooperation. Empirical evidence from European collaboration choices in Micro and nanotechnologies, Papers in Regional Science, 86(3): 495-519.

Autant-Bernard C. and LeSage J. (2010) Quantifying knowledge spillovers using spatial econometric tools, Journal of Regional Science, no. doi: 10.1111/j.1467-9787.2010.00705.x.

Autant-Bernard C., Billand P. and Massard M. (2010) Innovation and space - From externalities to networks (with Pascal Billand and Nadine Massard), in Johansson, Karlsson and Stough (eds.), Knowledge and Talent in Regional and Global Context, Edward Elgar, forthcoming.

Autant-Bernard C., Guironnet J-P. and Massard N. (2011) Agglomeration and social return to R\&D: Evidence from French plant productivity changes, International Journal of Production Economics, doi:10.1016/j.ijpe.2011.02.028.

Balconi M., Breschi S. and Lissoni F. (2004) Networks of inventors and the role of academia: an exploration of Italian patent data, Research Policy 33: 127-145.

Baltagi B., Song S.H., Jung B.C. and Koh W. (2007) Testing for serial correlation, spatial autocorrelation and random effects using panel data, Journal of Econometrics 140: 5-51.

Barbesol Y. and Briant A. (2009) Economies d'agglomération et productivité des entreprises : estimations sur données individuelles françaises, Economie et Statistique, 419420: 31-54. 
Bergman E.and Usai S. (2009) Knowledge Diffusion in European Regions, IAREG Delivrable 4.1.

Bottazzi L., Peri G. (2007) The internation dynamics of R\&D and innovation in the long run and in the short run, The Economic Journal, $117: 486-511$.

Breschi S. and Lissoni F. (2006) Mobility of inventors and the geography of knowledge spillovers. New evidence on US data. ADRES conference, Saint-Etienne, 14-15 september.

Breschi S. and Lissoni F, (2009) Mobility of skilled workers and co-invention networks: an anatomy of localized knowledge flows, Journal of Economic Geography, 9(4): 439-468.

Caniëls M. (1998) The Geographic Distribution of Patents and Value Added Across European, Research Memoranda 003, Maastricht: MERIT, Maastricht Economic Research Institute on Innovation and Technology.

Erthur C., Debarsy N. and LeSage J. (2010) Interpreting Dynamic Space-Time Panel Data Models, working paper.

Feldman M. (1994) The geography of innovation, Kluwer Academic Publishers, Dordrecht, Boston, Londres, pp.153.

Fischer, M.M., Scherngell, T. and Jansenberger, E. (2006): The geography of knowledge spillovers between hightechnology firms in Europe: Evidence from a spatial interaction modelling perspective, Geographical Analysis 38(3): 288-309.

Fischer, M.M. and Griffith, D.A. (2008): Modeling spatial autocorrelation in spatial interaction data: An application to patent citation data in the European Union, Journal of Regional Science 48(5): 969-989. 
Frachisse D. (2011) Structures et déterminants des collaborations au sein des programmes cadres de recherche et développement technologique de l'Union Européenne. Une perspective réseau, Thèse de doctorat.

Fujita M., Krugman P., Venables A. (1999) The Spatial Economy: Cities, Regions and International Trade, Cambridge (Mass.), MIT Press.

Gallié E.-P. and Legros D. (2007) Spatial spillovers in France: A study on individual count data at the city level, Annales d'Economie et Statistique, 2007, 87-88: 221.

Glaeser E., Kallal H., Scheinkman J. and Shleifer A. (1992) Growth in cities, Journal of Political Economy, 100(6) : 1126-1152.

Gomes-Casseres B., Hagedoorn J. and Jaffe A. (2006) Do alliances promote knowledge flows?, Journal of Financial Economics, 80(1): 5-33.

Hanaki N., Nakajima R., Ogura Y. (2009) The Dynamics of R\&D Network in the IT Industry, working paper

Henderson J., Kuncoro A. andd Turner, M. (1995) Industrial Development in Cities, Journal of Political Economy, 103: 1067-1090.

Hoekman J., Frenken K. and Tijsen R.J.W. (2010) Research Collaboration at a Distance: Changing Spatial Patterns of Scientific Collaboration within Europe, Research Policy, 39: 662 $-673$.

Jaffe A. (1989) Real effects of academic research, The American Economic Review, 79(5): 957-970. 
Jaffe A., Trajtenberg M. and Henderson R. (1993) Geographic localization of knowledge spillovers as evidenced by patent citations, The Quaterly Journal of Economics, August: 577598.

Johnson D., Siripong N. and Brown A. (2006) The Demise of Distance? The Declining Role of Physical Proximity for Knowledge Transmission, Growth and Change 37 (1): 19-33.

Jones C. (1995) R\&D-Based Models of Economics Growth, Journal of Political Economy, 103: 759-582.

Kapoor, M., Kelejian, H.H., and Prucha, I.R., (2007) Panel data models with spatially correlated error components, Journal of Econometrics 140: 97-130.

Lata R. and Scherngell T. (2010) The spatio-temporal distribution of European R\&D networks: Evidence using Eigenvector spatially filtered spatial interaction models, working paper.

Lee L-f. and Yu J. (2010) Some recent developments in spatial panel data models, Regional Science and Urban Economics, forthcoming.

LeSage J., Fischer M. and Scherngell T. (2007) Knowledge spillovers accross Europe:Evidence from a Poisson spatial interaction model with spatial effects, Papers in Regional Science, 86 (3): 393-422.

LeSage J. and Parent O. (2009) Spatial dynamic panel data models with random effects applied to highway induced vehicle travel demand, working paper.

LeSage, J. and Pace R. (2010) Introduction to Spatial Econometrics, Chapman and Hall/CRC Press, Taylor \& Francis Group. 
Maggioni M., Nosvelli M., Uberti E. (2007) Space vs. networks in the geography of innovation: A European analysis, Papers in Regional Science, 86(3): 471-493.

Maggioni M. and Uberti T. (2009) Knowledge networks across Europe: which distance matters?, The Annals of Regional Science, 43(3): 691-720.

Maggioni, M., Gambarotto F. and Uberti E. (2009), Mapping the Evolution of 'Clusters': A Meta-Analysis (October 15, 2009). FEEM Working Paper No. 74.2009.

Mairesse J. and B. Mulkay (2007) An exploration of local R\&D spillovers in France, Annales d'Economie et de Statistiques, 87-88: 145-166.

Marshall A. (1920), Principes d'économie politique, Gordon \& Breach, Paris, Londres, New York, reprint 1971, vol. 2, pp. 576.

Martin, P. T. Mayer and F. Mayneris (2011), Spatial Concentration and Plant-Level Productivity in France, Journal of Urban Economics 69(2):182-195.

Miguélez E. and Moreno R. (2010) Research Networks and Inventors' Mobility as Drivers of Innovation: Evidence from Europe, Working paper

Mika P., Elfing T. and Groenewegen P. (2006) Application of semantic technology for social network analysis in the sciences, Scientometrics, Vol. 68, No. 1, 3-27.

Paelinck J. and Klaassen L.H. (1979) Spatial Econometrics, Saxon House, Farnborough, 1979.

Parent O. and LeSage J. (2008) Using constraints on the variance structure of the conditional autoregressive specification to model knowledge spillovers, Journal of Applied Econometrics, 23(2): 235-256.

Parent O. (2009) A Space-Time Analysis of Knowledge Production, working paper 
Parent O. and LeSage J. (2010) A Spatial Dynamic Panel Model with Random Effects Applied to Commuting Times, Transportation Research, Part B: Methodological. 44B: 633-645.

Parent O. and LeSage J. (2011) A space-time filter for panel data models containing random effects, Computational Statistics and Data Analysis 55: 475-490.

Partridge M. and Rickman D. (1999) Static and dynamic externalities, industry composition and state labour productivity: a panel study of states, Southern Economic Journal, 66(2): 319-335.

Ponds R., Van Oort F. and Frenken K. (2007) The geographical and institutional proximity of research collaboration, 86(3): 341-524.

Romer P. (1990) Endogenous technological progress, Journal of Political Economy, 98(5): 71-102.

Scherngell T. and Barber M.J. (2009) Spatial Interaction Modelling of Cross-Region R\&D Collaborations: Empirical Evidence from the 5th EU Framework Program, Papers in Regional Science, 88(3): 531-546.

Snijders T., Steglich C., Schweinberger M. and Huisman M. (2007) Manual for siena version 3, University of Groningen and University of Oxford.

Singh J. (2005) Collaboration networks as determinants of knowledge diffusion patterns, Management Science, 51 (5): 756-770.

Sorenson O., Rivkin J.W., Fleming L. (2006) Complexity, networks and knowledge flow, Research Policy, 35: 994-1017. 
Su L. and Yang Z. (2007) QML Estimation of Dynamic Panel Data Models with Spatial Errors, Singapore Management University manuscript.

Ter Wal A. (2010) The Dynamics of the Inventor Network in German Biotechnology: Geographical Proximity versus Triadic Closure. Working paper

Vertova G. (2002) A historical investigation of the geography of innovative activities, Structural Change and Economic Dynamics, 13(3): 259-283.

Yu J., de Jong R. and Lee L-F. (2008) Quasi-Maximum Likelihood Estimators For Spatial Dynamic Panel Data With Fixed Effects When Both $n$ and $T$ Are Large, Journal of Econometrics, 146: 118-134.

Lee L-f. and Yu J. (2010) Estimation of spatial autoregressive panel data models with fixed effects, Journal of Econometrics 154:165-185.

Zucker L., Darby M. and Armstrong J. (1994) Intellectual Capital and the Firm: the Technology of Geographically Localized Knowledge Spillovers, NBER Working Paper Series, Working Paper no 4946, pp. 59.

'As shown for instance by Feldman (1994), Caniëls (1998) and Vertova (2002). 